\title{
Effect Of Online Reviews and Offline Cues on Consumer's Restaurant Selection: A Conceptual Model and Research Agenda
}

\author{
Muhammad Asghar Ali ${ }^{l^{*}}$, Ding Hooi Ting ${ }^{1}$, and Lina Salim ${ }^{2}$ \\ ${ }^{1}$ Universiti Teknologi PETRONAS, Malaysia \\ ${ }^{2}$ Atma Jaya Catholic University of Indonesia, Malaysia
}

Abstract. Write your abstract here

\section{Introduction}

The food industry is an important economic contributor to the Malaysian economy evolving at a faster rate. Dining establishments (like full-service restaurants, fast food, cafes and food stalls etc.) are offering a variety of cuisines (Chinese, Malay, Asian, Thai etc.) at a single destination. This variety of flavour always attracts tourist and domestic people's attention to food consumption. Majority of the Malaysian population is young, educated and involved in work-force, due to these demographic changes, consumers prefer to eat outside of the house at new places for convenience and change of taste. Moreover, Malaysia is a famous tourist place, in addition to the local people foreign tourist arrival help in boosting the Malaysian economy. It has been declared among the top 10 tourist destination of the world. Malaysian investment authority 2018 had shown the resolve to take tourism to new heights and they target to attract 36 million tourists to generate RM168 billion until 2020. Apart from international, Domestic tourism is also expanding and has depicted continuous doubledigit growth in expenditure from $10.2 \%$ (2016) to $11.1 \%$ in 2017 . In terms of value, local expenditure was recorded RM 74773 million (2016) as compared to a total of RM 83,103 million (2017). Consumers have spent 13.8 per cent of their income on food and beverages. Consumers spend a significant amount of their income on food consumption, which indicates the importance of the restaurant industry for Malaysian economic growth.

The invention of the internet has changed the way people interact and get product and services related information. Multiple online plate forms (web sites, social media blogs, Facebook pages etc.) are available which facilitate consumers to make informed decisions. (Minghetti and Buhalis 2010). Online web sites, social media and blogs etc. have reshaped the way people plan their visits. Now tourist can easily get all detailed information about their destination and other facilities like restaurants and shopping mall by a single click. Due to increasing consumer demand for food consumption outside the home, it is important to understand how consumers make restaurant selection decision after going through online reviews. The restaurant selection is not a simple process there are multiple of factors (like friends, family members, Servicescape etc.) can influence consumer restaurant selection and can have different implications for restaurant owners and researchers. Therefore, the principle aim of this study is to identify how consumers select a restaurant in an unfamiliar place.

Extensive research studies have been conducted on online reviews and their effect on consumer behaviour. Most of the studies concluded that positive online reviews generate positive attitude and influence consumer final choice. However, contrary to this some studies have emphasised that only intensions are not the only predictor of consumer final choice other factors like behavioural control, external stimuli (physical environment) can change consumer preexisting intentions and consumer behaviour in a different way (approach or avoidance). Moreover, Intentions do not always turn in to behaviour, It might be possible a person intent to visit a restaurant, but due to some external factor (friends' recommendation) might change the final choice. Therefore, a conceptual model has been proposed for this study in which online restaurant perception is the independent variable and consumer's purchase behaviour is the dependent variable. Offline cues and purchase intentions are shown as moderating and mediating variables respectively. Mix method technique will be used for data collection. In-depth interviews will be conducted to identify which online restaurant attributes considered important for restaurant selection and how offline sensation of restaurant attributes change final consumer choice. Moreover, quantitative data will be collected and Smart PLS will be used to empirically validate the results of the developed model.

\footnotetext{
* Corresponding author: muhammad_18003088@utp.edu.my
} 


\section{Online review, offline cues and purchase behaviour}

Online reviews are defined as "any positive or negative statements made by potential, actual, or former customers about their experiences, evaluations, and opinions on products and services" (Park \& Park, 2008, p. 744). Consumer's reviews are positive if they have a positive experience with the restaurant services and products and vice versa. Online reviews have become a major source of information for consumers to find a product or services that fit consumer needs (Chen and Xie, 2008). Research reports depict that $93 \%$ of consumers refer to online reviews for product or service-related information and this online information influence their final purchase decisions. They also state that consumers read an average of seven reviews to decide if a business is good (or not) (BrightLocal, 2017). Online reviews are potentially rich sources of information, the number of online reviews; online rating and valance have different implications for customer perception.

Online reviews facilitate information inflow and help to avoid poor decision making. For example, volume, review influences consumer choice, higher the volume of review higher the chances of that consumer will purchase from that restaurant (Park, Lee, \& Han 2007). In the same direction, Zhang et al. (2010) posit that online consumer rating is considered as a symbol of food quality, good restaurant environment and service quality, higher the online rating restaurant is believed to have excellent attributes. Moreover, the higher number of online reviews demonstrate restaurant is popular in online plate-form (Facebook page, web site etc.) (Kovács, Carroll, \& Lehman, 2013). Generally, consumers have to rate restaurant services within a continuum from one to five stars, whereby one star represents poor service and five stars represent excellent services. Review usefulness helps in measuring consumer perception of online reviews (Siering et al., 2018), it facilitates consumers in dealing huge flux of information available on online web sites for decision making (Cao et al., 2011).

Past literature elaborates that "reviewer characteristics" and review distinctiveness influence consumers "perceived usefulness" of online reviews ( $\mathrm{Li}$ et al., 2017; Liu and Park, 2015). For example, reviews of Elite reviewers influence consumer more than non-Elite equivalent and social acceptability of reviewer influence the review usefulness. Liu and Park (2015) report that review helpfulness is influenced by multiple factors, including the disclosure of reviewers' identities (e.g. name, address, real photo), reviewers' reputations (e.g. the number of fans, friends, Elite awards), and reviewers' expertise (e.g. the number of reviews the reviewer has written). Additionally, review characteristics such as the review sentiment, star rating, readability, length, and posting date all influence perceived review helpfulness (Li et al., 2017). Apart from reviewer characteristics and identity, existing emotional state also influences commenting intentions. As generally believed that emotionally charged people make irrational decisions, in the same way, sometimes satisfied (dissatisfied) consumers post more ambitious comments and overrate (underrate) restaurants characteristics which may mislead other consumers while making restaurant choice. Besides, the perception of each person is different from others; hence it is not necessary that the restaurant's attribute liked and shared by some consumers also appreciated by others in the same way. Therefore, each person has different food choices and preferences which can be satisfied with different combinations of attributes. Thus, online reviews do not seem to cover all aspects of information necessary for satisfactory decision making.

\subsection{Underpinning theory}

The signalling theory will be used to illustrate the phenomena of consumer attitude formation in the hospitality industry. Online reviews give important signals about different aspects of restaurant attributes (e.g., food quality, service quality, and environment), these signals develop consumer attitude about service environment which might lead to consumers positive purchase intentions. Hence Individuals don't perceive the product and places directly; instead, they look for various cues and signals within that specific context. Signals help in understanding hidden information and thus consumers depend on signals to proceed with any decision or choice. For instance, a car signals wealth, speaker's accent signals his country of origin etc. Similarly, restaurant attributes also signal the level of service quality that helps in consumer decision making for patronisation.

Extant research has analysed restaurant attributes based online review (Laurel, Sacramento, \& Pedron 2014; Pantelidis 2010). Most of the researcher in this direction have done the content analysis of online reviews and identified dimensions or attributes which consumers consider important about restaurant selection, and Food quality is one of the most important aspect frequently highlighted by consumers for restaurant selection Chaves et al. (2014). Furthermore, Chaves also provide a list of most frequent to least frequent restaurant attributes named as, staff and communication, price, atmosphere, a variety of menu, quality of service. Pantelidis (2010) also conducted his study on consumers experience in an online context and highlighted six well-known restaurant attributes that consumers take into account for final choice: food, service, atmosphere, the price was most important for the consumer while menu and design were least important. (Chaves et al., 2014; Pantelidis, 2010). The researcher proposes that consumers perceptions of restaurants attribute prior visit are just their perceived imagination about a particular place for which consumer is interested and yet to visit. Due to intangibility of services, shared photos, videos in reviews does not allow the consumer to see, feel, sense, taste anything well in an online setting as can be done in a real environment. 
The researcher proposes that real setting offline environmental attributes can have a different effect on consumer attitude as compared to perception or attitude developed based on online reviews. Moreover, consumer misconceptions about online reviews might also create a lack of trust and reduce its influence on final choice in a real environment. This emphasises the importance of offline cues or signals and environmental attributes which consumer might observe different from the information given on online platforms. There can be many reasons for this difference. Firstly, reviews of unfamiliar people do not depict originality and undermine consumer trust on authenticity. Secondly, until now, there is no proper online mechanism or filter available which can identify fake reviews and ensure the authenticity of online reviews. Another attribution about online reviews consumers' awareness that Reviews can be manipulated due to lack of controllability by the user. Companies or organisations can easily delete negative views and only show positive reviewers to attract users or customers. Apart from deleting they can also change the sequence of online reviews, negative reviews are hidden, most of the time positive reviews are shown on the top of Facebook page and web site page so that these can influence customer's perception positively regarding the performance of the company.

Despite organisations and putting efforts for review management, the practice of using fake id to disseminate fake information is still a challenge for business and consumers. Competitors can use unethical practices to undermine the reputation of an organisation by posting negative online reviews. By keeping in view these kinds of issues, big companies like Amazon.com include additional web site features to make sure reviews come from an authentic source (genuine consumer). Despite the effort to identify fake online reviews, organisations still lack control on the transparency of online review as some organisations themselves manipulate online review to show a positive image of the company, the delete negative reviews and maintain the positive for consumer attention-seeking (Hu, Bose, Koh \& Liu 2011). A survey report by Maritz Research (Ensing 2013) identified consumers usually go to online platforms to gather product and servicerelated information. However, they are skeptical as provided information might be fake due to various reasons. Therefore, the online reviews do not show a complete picture and offline reality can be different what is shown and said at online plate form. Therefore, it will be interesting to know, do intentions developed based on online review translate into actual behaviour and how environmental cues change final consumer choice. Online reviews are considered an important source of information for prospective customers. However, sensorial experience of the physical appearance of restaurant attributes can change final consumer choice.

Extensive previous studies have highlighted the importance of offline restaurant attributes named as physical environment, SERVICESCAPE, DINESERVE and DINESCAPE. Kotler (1973) defined the physical environment as a surrounding that creates a particular emotional effect and influence consumer buying behaviour. Besides these terms, some researchers have identified different dimensions of the physical environment. These dimensions consist of ambient aspects, design aspects, spatial layout, functionality, artefacts, reliability, responsiveness, empathy, assurance, tangibles internal (building design) and external variables (car parking, working hours), seating arrangements, facility cleanliness, lighting table setting, service staff and social factor (Baker, 1987; Bitner, 1992, Berman and Evans, 1995; Stevens et al., 1995; Wakefield and Blodgett, 1996; Raajpoot, 2002; Lucas, 2003; Newman, 2007; Ryu and Jang, 2008a). The reason of emphasis on the physical environment is the financial and strategic importance of these factors that influence consumer emotions, service evaluation, satisfaction and service quality (Bitner, 1990; Ryu and Jung, 2008b).

Moreover, intangible nature of service sector also another reason of the importance of physical environment because it facilitates in hedonic consumption and consumers tend to spend a lot of time in a good service environment (Wakefield and Blodgett, 1994; Ryu and Jang, 2007). Finkelstein (1989) posited that consumers make restaurant preference based on their psychological needs rather than physical needs. Hence "meals consist of much more than the food to be eaten" Gustafsson $(2004,11)$. Milliman (2017) posited that sometimes physical restaurant environment plays a more dominant role in consumer choice than other factors or product itself. Therefore, if the consumer perceives restaurant attributes attractive in online reviews and less-inviting offline, they may choose another restaurant to dine. Restaurant physical environment has been reported to influence customers in physiological, cognitive, emotional as well as psychological and sociological ways.

Therefore, the researcher developed the following proposition for this conceptual paper:

P1: Online reviews attributes will cause consumers to purchase intentions.

P2: Intentions will predict consumer purchase behaviour

P2: Perceptions of offline consumer cues will moderate the intentions-behaviour gap. 


\subsection{Conceptual Framework:}

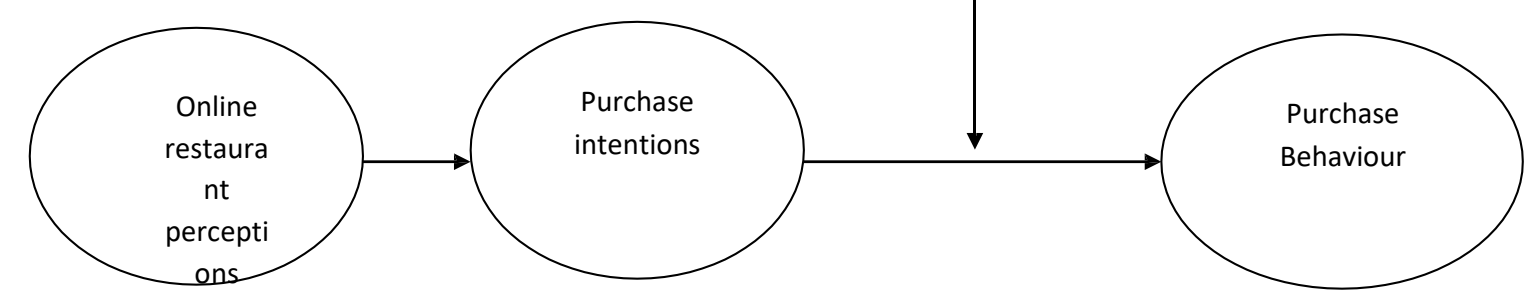

Fig.

\section{Conclusion and future research}

This paper highlighted the concerns of past studies where purchase intentions were measured as a proxy of purchase behaviour. Hence it will be interesting to test intentions developed in virtual word and their implication in actual consumer purchase behaviour with the moderating role of offline cues. This paper discussed a sound approach to investigate consumer actual purchase behaviour and with a more rigorous method of data collection and analysis. The proposed model will incorporate several factors of online restaurant perceptions and offline environmental cues to explain consumer actual purchase behaviour. This leads us to the development of the conceptual framework as shown in figure 1. Moreover, the literature on consumer purchase behaviour mostly focused on time and money spent in a particular consumption situation however many other aspects of consumer purchase behaviour are still yet to determine because these two dimensions do not comprehensively cover all aspects of consumer purchase behaviour. Therefore, it is imperative to develop and validate the scale of consumer actual purchase behaviour in the restaurant setting. This framework can be applied in a different context and maybe benefited by including longitudinal and cross-sectional studies in different geographic regions and cultural settings.

\section{References}

Anderson, E. W. (1998). Customer satisfaction and word of mouth. Journal of service research, 1(1), $5-17$.

Baker, D. H., \& Halpin, K. M. (1987). Research note: Efficacy of a manganese-protein chelate compared with that of manganese sulfate for chicks. Poultry science, 66(9), 1561-1563. 
Bansal, H. S., \& Voyer, P. A. (2000). Word-of-mouth processes within a services purchase decision context. Journal of service research, 3(2), 166-177.

Berman, B., \& Evans, J. R. (1995). Retail management: A strategic approach (Doctoral dissertation, Univerza v Mariboru, Ekonomsko-poslovna fakulteta).

Bitner, M. J. (1992). Servicescapes: The impact of physical surroundings on customers and employees. Journal of marketing, 56(2), 57-71.

Cao, S., Sun, G., Zhang, Z., Chen, L., Feng, Q., Fu, B., ... \& Wei, X. (2011). Greening China naturally. Ambio, 40(7), 828831.

Chatterjee, P. (2001). Online reviews: do consumers use them?

Chaves, M. S., Laurel, A., Sacramento, N., \& Pedron, C. D. (2014). Fine-grained analysis of aspects, sentiments and types of attitudes in restaurant reviews. Tourism \& Management Studies, 10(1), 66-72.

Chen, Y., \& Xie, J. (2008). Online consumer review: Word-of-mouth as a new element of marketing communication mix. Management science, 54(3), 477-491.

Ensing, D. (2013). Customer Rating and Reviews Site: An Upcoming Crisis of Confidence?. Maritz Research, July.

Gustafsson, I. B. (2004). Culinary arts and meal science-a new scientific research discipline. Food Service Technology, 4(1), 9-20.

Hu, N., Bose, I., Gao, Y., \& Liu, L. (2011). Manipulation in digital word-of-mouth: A reality check for book reviews. Decision Support Systems, 50(3), 627-635.

Hung, K. H., \& Li, S. Y. (2007). The influence of eWOM on virtual consumer communities: Social capital, consumer learning, and behavioral outcomes. Journal of advertising research, 47(4), 485-495.

Katz, E., \& Paul, F. (1955). Lazarsfeld (1955), Personal Influence. The Part Played by People in the Flow of Mass Communication. New York.

Kotler, P. (1973). Atmospherics as a marketing tool. Journal of retailing, 49(4), 48-64.

Kovács, B., Carroll, G. R., \& Lehman, D. W. (2013). Authenticity and consumer value ratings: Empirical tests from the restaurant domain. Organization science, 25(2), 458-478.

Lee, Y., Lee, H., Kim, Y. B., Kim, J., Hyeon, T., Park, H., ... \& Park, T. G. (2008). Bioinspired surface immobilization of hyaluronic acid on monodisperses magnetite nanocrystals for targeted cancer imaging. Advanced Materials, 20(21), 4154-4157.

Li, L., Zhang, J., Nian, S., \& Zhang, H. (2017). Tourists' perceptions of crowding, attractiveness, and satisfaction: a second-order structural model. Asia Pacific Journal of Tourism Research, 22(12), 1250-1260. doi:10.1080/10941665.2017.1391305.

Liu, Z., \& Park, S. (2015). What makes a useful online review? Implication for travel product websites. Tourism Management, 47, 140-151.

Liu, Z., \& Park, S. (2015). What makes a useful online review? Implication for travel product websites. Tourism Management, 47, 140-151.

Mayer, M. L., \& Westbrook, G. L. (1987). Permeation and block of N-methyl-D-aspartic acid receptor channels by divalent cations in mouse cultured central neurones. The Journal of physiology, 394(1), 501-527.

Milliman, J., \& Clair, J. (2017). Best environmental HRM practices in the US. In Greening People (pp. 49-73). Routledge.

Minghetti, V., \& Buhalis, D. (2010). Digital divide in tourism. Journal of Travel Research, 49(3), $267-281$.

Newman, A. J. (2007) Uncovering dimensionality in the servicescape: Towards legibility. The Service Industries Journal, $27(1)$, pp. $15-28$

Pantelidis, I. S. (2010). Electronic meal experience: A content analysis of online restaurant comments. Cornell Hospitality Quarterly, 51(4), 483-491.

Park, D. H., Lee, J., \& Han, I. (2007). The effect of on-line consumer reviews on consumer purchasing intention: The moderating role of involvement. International journal of electronic commerce, 11(4), 125-148.

Raajpoot, N. A. (2002). TANGSERV: A multiple item scale for measuring tangible quality in foodservice industry. Journal of Foodservice Business Research, 5(2), 109-127.

Ryu, K., \& Jang, S. (2008). DINESCAPE: A scale for customers' perception of dining environments. Journal of Foodservice Business Research, 11(1), 2-22.

Ryu, K., \& Jang, S. S. (2007). The effect of environmental perceptions on behavioral intentions through emotions: The case of upscale restaurants. Journal of Hospitality \& Tourism Research, 31(1), 56- 72 
Siering, M., Muntermann, J., \& Rajagopalan, B. (2018). Explaining and predicting online review helpfulness: The role of content and reviewer-related signals. Decision Support Systems, 108, 1.

Stevens, P., Knutson, B., \& Patton, M. (1995). DINESERV: A tool for measuring service quality in restaurants. The Cornell Hotel and Restaurant Administration Quarterly, 36(2), 5-60

Wakefield, K. L., \& Blodgett, J. G. (1996). The effect of the servicescape on customers' behavioral intentions in leisure service settings. Journal of Services Marketing, 10(6), 45-61. doi:10.1108/08876049610148594

Zhang, P., Zhang, X., Brown, J., Vistisen, D., Sicree, R., Shaw, J., \& Nichols, G. (2010). Global healthcare expenditure on diabetes for 2010 and 2030. Diabetes research and clinical practice, 87(3), 293-301.

Zhang, P., Zhang, X., Brown, J., Vistisen, D., Sicree, R., Shaw, J., \& Nichols, G. (2010). Global healthcare expenditure on diabetes for 2010 and 2030. Diabetes research and clinical practice, 87(3), 293-301

Zhou, L., Dai, L., \& Zhang, D. (2007). Online shopping acceptance model-A critical survey of consumer factors in online shopping. Journal of Electronic commerce research, 8(1) 